Lyall, A. (1935) Massive extramedullary bone marrow formation in a case of pernicious anaemia. Journal of Pathology and Bacteriology, 41, 469.

MARINOZZI, V. (1958) Aspetti insoliti dell'iperplasia midollare nelle anemie emolitiche. Haematologica, 43, 737.

Plonskier, M. (1930) Über tumorformige (extramedullare heterotope) subpleurale Knochenmarksherde. Virchows
Archiv für pathologische Anatomie und Physiologie und fïr klinische Medizin. Berlin, 277, 804.

SORSDAHL, O.S., TAyloR, P.E. \& Noyes, W.D. (1964) Extramedullary hematopoiesis, mediastinal masses and spinal cord compression. Journal of the American Medical Association, 189, 343.

Postgraduate Medical Journal (July 1977) 53, 397-399.

\title{
A case of Bacillus cereus bacteraemia
}

\author{
M. BARNHAM \\ M.B. B.S.
}

\author{
A. J. TAYLOR \\ M.Sc., F.I.M.L.S.
}

Department of Diagnostic Bacteriology, St Mary's Hospital Medical School, London, W2

\begin{abstract}
Summary
A case is presented of Bacillus cereus bacteraemia in a patient receiving hepatic perfusion with 5 -fluorouracil (5FU) for metastasis from a carcinoma of the breast. The literature concerning systemic $B$. cereus infections is briefly reviewed.
\end{abstract}

\section{Case report}

In May 1974, a 66-year-old woman underwent local excision for a poorly differentiated polygonalcell carcinoma of the left breast. She also had a right-sided malignant pleural effusion which was treated with stilboestrol and local instillation of mepacrine. In December 1974, she suffered a local recurrence of the tumour in the breast and was treated with a course of radiotherapy.

In August 1975, the patient was readmitted complaining of tiredness, anorexia and loss of weight. Examination revealed an enlarged liver, three fingers breadth below the costal margin. Investigations showed $\mathrm{Hb} 13.2 \mathrm{~g} / \mathrm{dl}$; WBC $7.5 \times 10^{\circ} / 1$; plasma proteins $64 \mathrm{~g} / \mathrm{l}$; bilirubin $71 \mu \mathrm{mol} / \mathrm{l}$ (normal 5-17 $\mu \mathrm{mol} / \mathrm{l}$ ); alkaline phosphatase 320 u./l (normal 20-95 u./l); aspartate transaminase $76 \mathrm{u} . / 1$ (normal 4-17 u./l) and blood glucose $4.9 \mathrm{mmol} / \mathrm{l}$. A liver scan revealed multiple hepatic secondary deposits; a radiographic skeletal survey showed no evidence of metastasis to bone.

On 11 August, laparotomy was performed and a cannula was inserted into the hepatic artery; multiple hepatic secondary deposits were confirmed by biopsy. After the operation she was treated with $750 \mathrm{mg}$ 5-fluorouracil instilled through the cannula by slow injection once a week; the cannula was flushed with $1 \mathrm{ml}$ of a $1: 1000$ solution of heparin twice a day. The site around the cannula remained clean, with swabs yielding no bacterial growth until 1 September, when a serous fluid began to leak from around the cannula and a swab yielded a moderate growth of $B$. cereus and Staphylococcus albus. Paracentesis was performed and a small quantity of ascitic fluid withdrawn, but culture yielded no bacterial growth. On the following day, a blood culture was taken from an arm vein and after $18 \mathrm{hr}$ incubation this yielded $B$. cereus from two of three bottles. $B$. cereus was again isolated from the cannula site on 4 September, although a Gram film showed only scanty polymorphs and the site was clinically improved. The site was found still to be colonized with B. cereus 12 days later. Further blood cultures were taken but the organism was not recovered again.

Throughout this episode, the patient remained well and apyrexial and she required no antibiotic therapy. Associated with the infection was a transient rise in blood glucose $(11.3 \mathrm{mmol} / \mathrm{l}$ on 1 September) and a neutrophil leucocytosis reaching a peak WBC of $17.5 \times 10^{9} / 1$ a few days after the isolation from the blood culture.

Doses of 5-fluorouracil had been administered through the cannula on 29 August and 5 September.

The isolates of $B$. cereus were identified using the methods described by Gilbert and Taylor (1976) and were typed as serotype 2 with the flagella antigen scheme of Taylor and Gilbert (1975). The bacteria showed a typical susceptibility pattern, being sensitive in vitro to neomycin, gentamicin, kanamycin, tetracycline and clindamycin; moderately sensitive to erythromycin and resistant to ampicillin, penicillin, methicillin, cephaloridine and sulphamethoxazole. 


\section{Discussion}

B. cereus has attracted renewed interest after its recent recognition as a causative agent of food poisoning. In the U.K. this illness has been characterized by the rapid onset of vomiting especially associated with the consumption of rice from Chinese restaurants and 'take-away' shops (Mortimer and McCann, 1974; Gilbert and Taylor, 1975). Although the illness is usually brief, relatively mild and limited to intestinal disturbance more serious symptoms can occur, as in the case described by Gutkin (1975) which showed gross dehydration followed by periorbital oedema. Outbreaks of food poisoning in many other countries have been described (Goepfert, Spira and Kim, 1972) but have generally resembled Clostridium welchii food poisoning, with a slow onset and with diarrhoea as the main feature.

A variety of local and systemic infections with B. cereus has been described. Early reports contain references to Bacillus infections of the eye ranging from acute conjunctivitis to panophthalmitis (Davenport and Smith, 1952). B. cereus has been reported in cases of bacteraemia following the use of contaminated haemodialysis apparatus (Curtis, Wing and Coleman, 1967), following road traffic accident injuries (Goullet and Pepin, 1974) and in a drug addict with endocarditis (Craig, Wie-Ching and Monto, 1974). Haemorrhagic pneumonia with septicaemia was reported in a previously healthy man (Stopler, Camuescu and Vioculescu, 1965) and in a patient with lymphocytic leukaemia (Coonrod, Leadley and Eickhoff, 1971a). Meningitis in a patient with ventriculoatrial shunt has been reported (Leffert, Baptist and Gidez, 1970) and Farrar (1963) described several cases of Bacillus meningitis.

Coonrod, Leadley and Eickhoff (1971b) studied the antibiotic susceptibility of several species of Bacillus and found tetracycline, kanamycin and chloramphenicol active against nearly all their strains. They found $B$. cereus to be the most resistant species to penicillins and cephalosporins and this correlates with its known production of $\beta$-lactamase; (Sabbath and Abraham, 1965). Enzymes from $B$. cereus and other Bacillus species may be of clinical importance in mixed infections if a penicillin is used for antimicrobial therapy as they may destroy the drug, sheltering other genuinely sensitive pathogens.

In the present case the hepatic cannula site appeared to be free from infection for the first three weeks after operation. The bacteraemia episode followed 1 day after the first isolation of $B$. cereus from the site, where there were signs of local infection. It is not clear whether the organism reached the blood stream directly from the local infection or by being flushed down the cannula with the heparin solution; the latter possibility seems less likely. The infection was mild, resolving spontaneously without antibiotic treatment, although the colonization of the cannula site persisted for at least 2 weeks. B cereus is commonly found in the environment and it is presumed that the infection was of extraneous origin.

Bacillus spp. are often encountered in the laboratory as contaminants and, unless there is good liaison between the pathologist and clinicians, their role in genuine infection can be easily overlooked. Isolation of the organism from several specimens in a case may be helpful in establishing its significance, particularly if it is cultured from sites which are normally sterile. Opportunities for infection with so-called 'low-grade' pathogens are increasing with the wider application of adventurous medical and surgical treatment and the prolonged survival of compromised patients. Isolates from such cases require particularly careful examination. In the present case the presence of an indwelling cannula, the cytotoxic therapy and the underlying carcinomatosis may each have played its part in predisposing to the infection.

\section{Acknowledgment}

We are grateful to Professor H. A. F. Dudley for permission to publish this case and to members of his surgical team for help in preparation of the clinical report.

\section{References}

CoOnRod, J.D., Leadley, P.J. \& EickhofF, T.C. (1971a) Bacillus cereus pneumonia and bacteremia. American Journal of Respiratory Diseases, 103, 711.

Coonrod, J.D., Leadley, P.J. \& Eickhoff, T.C. (1971b) Antibiotic susceptibility of Bacillus species. Journal of Infectious Diseases, 123, 102.

Craig, C.P., Wie-Ching, L. \& Monto, H. (1974) Bacillus cereus endocarditis in an addict. Annals of Internal Medicine, 80, 418.

Curtis, J.R., Wing, A.J. \& Coleman, J.C. (1967) Bacillus cereus bacteraemia. A complication of intermittent haemodialysis. Lancet, i, 136.

DavenPort, R. \& SMith, C. (1952) Panophthalmitis due to an organism of the Bacillus subtilis group. British Journal of Ophthalmology, 36, 389.

Farrar, W.E. (1963) Serious infections due to 'non-pathogenic' organisms of the genus Bacillus. American Journal of Medicine, 34, 134.

GilberT, R.J. \& TAYlor, A.J. (1976) Bacillus cereus food poisoning. In: Microbiological Trends in Agriculture, Fisheries and Foods. (Society for Applied Bacteriology Symposium Series No. 4) Academic Press, London.

GilberT, R.J. \& TAYlor, A.J. (1975) Outbreaks of Bacillus cereus food poisoning in Great Britain. Zentralblatt für Bakteriologie, Parasitenkunde, Infektionskrankheiten und Hygiene. I. Referate, 242, 163.

Goepfert, J.M., Spira, W.M. \& Kim, H.U. (1972) Bacillus cereus food poisoning. A review. Journal of Milk and Food Technology, 35, 213.

Goullet, O. \& PePin, H. (1974) Une septicémie à Bacillus cereus. Nouvelle Presse médicale, 38/40, 2490.

GUTKIN, B.J. (1975) Bacillus cereus intoxication followed by periorbital oedema. British Medical Journal, 4, 24. 
Leffert, H.L., BaPtist, J.N. \& Gidez, L.I. (1970) Meningitis and bacteremia after ventriculoatrial shunt revision: isolation of lecithinase producing Bacillus cereus. Journal of Infectious Diseases, 122, 547.

Mortimer, P.R. \& MCCANN, G. (1974) Food poisoning episodes associated with Bacillus cereus in fried rice. Lancet, i, 1043.

Sabbath, L.D. \& Abraham, E.P. (1965) Cephalosporinase and penicillinase activity of Bacillus cereus. Antimicrobial Agents and Chemotherapy, 392.

Stopler, T., Camuescu, V. \& Vioculescu, M. (1965) Bronchopneumonia with lethal evolution determined by a micro-organism of the genus Bacillus (B. cereus). Revue Roumaine de Médecine, 19, 7.

TAYLOR, A.J. \& GilberT, R.J. (1975) Bacillus cereus food poisoning: a provisional serotyping scheme. Journal of Medical Microbiology, 8, 543.

\title{
Diaphragmatic flutter
}

\author{
C. L. CorbetT \\ M.B., Ch.B., M.R.C.P.(U.K.) \\ Department of Medicine, University of Manchester School of Medicine, \\ Hope Hospital, Eccles Old Road, Salford M6 8HD
}

\begin{abstract}
Summary
A case is reported of diaphragmatic flutter with an unusually long duration of symptoms. The patient described demonstrates many of the classical features of this disorder.

\section{Introduction}

Diaphragmatic flutter is a rarely diagnosed disorder (Rigatto and DeMedeiros, 1962) and, because of the frequently bizarre symptomatology, diagnosis may be delayed, and referral for psychiatric assessment is common. The true cause of the symptoms is often only apparent when an attack is witnessed, or during X-ray screening, and it seems likely that some cases go undetected.
\end{abstract}

\section{Case report}

A Saudi Arabian female, first presented at the age of 15 years in 1957 with attacks of pain in the upper abdomen and lower chest, radiating round the lower ribs on the left side and down the left arm. The onset of pain was briefly preceded by marked epigastric pulsations and loud, rhythmical, splashing sounds. These features lasted for 2-15 min, whilst the pain persisted for up to a further $30 \mathrm{~min}$. The frequency of attacks was very variable, sometimes occurring ten to fifteen times a day. Periods of freedom seldom exceeded 2 weeks. The attacks did not occur during sleep. Before correct diagnosis, she

Correspondence: Dr C. L. Corbett, The Royal Infirmary, Sheffield S6 3DA. underwent appendicectomy, intercostal injections of local anaesthetics, numerous drug therapies and psychiatric referral. A laparotomy and pyloroplasty were performed in 1967 and conversion to a gastrojejunostomy a week later for persistent vomiting. In 1968 diaphragmatic flutter involving the left hemidiaphragm was diagnosed by X-ray screening during a visit to London. Temporary relief from attacks was obtained by infiltration of the left phrenic nerve in the neck with local anaesthetic, and surgical crushing of the nerve was then carried out. This produced relief from symptoms for 3 months. This procedure was repeated, producing a further 1 month's freedom from attacks. Her symptoms then recurred, together with intermittent vomiting and continued up to her return to this country and referral to Professor L. A. Turnberg in July 1975.

On admission she was well nourished, and physical examination and biochemical investigations were normal. Many attacks of diaphragmatic flutter were witnessed during her stay in hospital. Each attack began with marked epigastric pulsations, vigorous enough to cause the whole bed to shake, and a bizarre rhythmical splashing sound which was audible from a distance of several yards, and loud enough to awaken nearby patients. She complained of severe pain and was obviously dyspnoeic, and a venous blood carbon dioxide content of $15 \mathrm{mmol} / \mathrm{l}$ was found on one occasion. A regular tachycardia of $120 /$ min was noted during attacks and the blood pressure was unchanged. The epigastric pulsations 